\title{
Sexual health concerns in women with intellectual disabilities: a systematic review in qualitative studies
}

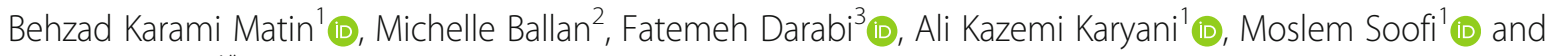
Shahin Soltani ${ }^{1 *}$ (D)

\begin{abstract}
Background: Studies indicate that women with intellectual disabilities (ID) face various personal and socioenvironmental barriers in their sexual lives. This study aimed to identify the concerns and sexual health needs experienced by women with ID.
\end{abstract}

Method: A systematic review of relevant qualitative articles was conducted in PubMed, Web of Science Scopus and PsycINFO databases from June 2018 to August 2018. We designed our search strategy according to two main foci: (1) sexuality; and (2) women with ID. In the study, searches were limited to articles published from January 2000 to December 2017. In this review, studies on women ages 16 and over were included.

Results: Within the four databases, the search found 274 unique articles. After three steps of screening (title, abstract and full text), 22 studies were included in the final review. The articles mentioned difficulties with lack of sexual experience, negative experiences with sexuality, negative attitudes towards sexuality by nondisabled individuals, limited cognitive capacities to understand sexual identity, difficulty with finding the right partner, lack of access to sexual health information, lack of school-based sexuality education, violence and sexual abuse, lack of support from families and caregivers about sexuality, fear of sexual acts and unwanted pregnancy, shyness in expressing sexual desires, and limited knowledge of sexual behaviors.

Conclusion: Our findings indicate that women with ID need to be provided with school-based sexuality education tailored to the level of understanding needed to attain the requisite knowledge to form relationships, understand sexual and romantic relationships, and practice safe sex when they choose this option. Families along with education and healthcare systems should provide opportunities for women with ID to talk about their sexual needs and make their own choices.

Keywords: Sexual health, Sexuality, Sex education, Intellectual disability, Qualitative studies, Systematic review

\footnotetext{
* Correspondence: sh-soltani@alumnus.tums.ac.ir

${ }^{1}$ Research Center for Environmental Determinants of Health, Health Institute, Kermanshah University of Medical Sciences, Kermanshah, Iran

Full list of author information is available at the end of the article
}

(c) The Author(s). 2021 Open Access This article is licensed under a Creative Commons Attribution 4.0 International License, which permits use, sharing, adaptation, distribution and reproduction in any medium or format, as long as you give appropriate credit to the original author(s) and the source, provide a link to the Creative Commons licence, and indicate if changes were made. The images or other third party material in this article are included in the article's Creative Commons licence, unless indicated otherwise in a credit line to the material. If material is not included in the article's Creative Commons licence and your intended use is not permitted by statutory regulation or exceeds the permitted use, you will need to obtain permission directly from the copyright holder. To view a copy of this licence, visit http://creativecommons.org/licenses/by/4.0/ The Creative Commons Public Domain Dedication waiver (http://creativecommons.org/publicdomain/zero/1.0/) applies to the data made available in this article, unless otherwise stated in a credit line to the data. 


\section{Background}

Sexuality has a complex role in our lives and can influence one's quality of life. Although sexuality can be a source of happiness and wellness, it also raises some ethical and cultural concerns in different societies [1]. According to the World Health Organization (WHO), sexual health is "the state of physical, emotional, mental and social well-being in relation to sexuality, and requires a positive and respectful approach to sexuality and sexual relationship." The World Association for sexual Health, identifies different factors such as attitudes, sexual behaviors, societal determinants, biological factors and genetic disorders as influencing sexual health [2].

One group specifically impacted by lack of access to sexual health resources is women with intellectual disabilities (ID). ID is described as a disability of intellectual functioning and adaptive behavior that occurs during the period of time from conception to the beginning of adulthood. An individual With ID experience meaningful limitations in both intellectual ability and adaptive behavior that onset before the age of 18 [3]. Studies indicate that people with ID face various personal and socioenvironmental barriers in their sexual lives. Some of these barriers include limited sexual knowledge, poor education, negative attitudes, lack of access to healthcare, lack of sexual experiences, and social isolation which can lead to increased sexual violence and abuse of women with ID [4-6]. Lack of awareness of sexual health can also result in sexually offensive behaviors among people with ID [7, 8]. Studies highlight that people with ID have problems expressing their sexual needs $[9,10]$. Findings show that some people with ID do not have enough information about their sexual identity [11]. Lack of sexual health education contributes to increased prevalence of sexually transmitted infections among people with ID including an increased risk of HIV infection $[11,12]$.

Lack of knowledge about sexuality coupled with limited sexual experiences, language difficulties, communication problems, fear, embarrassment, low self-esteem and poor negotiating skills can increase exposure to unsafe situations for women and men with ID [13-15]. Esmail et al. note that the lack of access to information can perpetuate negative attitudes and misconceptions about women with ID [16]. These negative attitudes and beliefs can affect sexual functioning, intimate relationships, promotion of sexual health, safety, procreation, access to sexual health information and participation in sexuality education programs for women with ID [17-19].

Furthermore, healthcare systems can limit access to sexual health services for women with ID. Studies indicate that there is no consensus across providers on the approaches to sexuality education for this population [20]. For example, physicians are aware of sexually transmitted diseases among women with ID, however studies indicate they are less likely to have mammograms and pap smears compared to their nondisabled counterparts [21, 22]. Also administrative barriers such as funding shortages and lack of policy guidelines impact access to sexual health services for people with ID [20].

The sexuality of women with ID is not a new focus within the literature. However, access to sexual health services is an understudied and necessary foci in healthcare research for this population. Different studies have been conducted to identify the sexual health needs of both men and women with ID. In this study, we intend to provide a comprehensive overview of the challenges women with ID face regarding sexual health promotion. Thus, the main research question, according to PICOS, posed was: "What are the needs and concerns of women with ID (age>16 years old) regarding their sexual heath?" We examined the question from different perspectives (women with ID, families, and healthcare providers) to achieve a more complete and deeper understanding of the role of sexual health promotion among women with ID, with specific attention to the unique challenges to access sexual health services in low and high income countries. Through this review, we hope the findings are helpful to researchers, policy makers, providers, selfadvocates and other stakeholders who address the needs and concerns of women with ID and the barriers they face.

\section{Method}

\section{Selection of studies}

To investigate and identify the sexual health needs of women with ID, we decided to include only qualitative study designs in this review. There were three reasons to focus on this type of study. First, qualitative studies can provide a deep understanding of participant's attitudes, beliefs, interactions, experiences and behaviors [23]. Second, some concerns and needs in sexual health may be unique among the participants that are not reflected completely in quantitative studies. Third, in qualitative studies, researchers are able to evaluate human behaviors more extensively than quantitative studies [23]. Thus, the observational studies (case-control, prospective, cross-sectional studies), experimental (quasi-experimental and randomized controlled trials), and review articles (narrative, scoping and systematic reviews) were excluded. In this study, young women with intellectual disabilities (older than 16) were included. Sixteen was selected to represent the age of consent for sexual relations in many countries, however the age to consent in some countries or states may be lower or higher.

In addition, we excluded non-English language studies and grey literature (such as books, dissertations, conference abstracts) from the research. For studies without 
full text access, we sent an email to the authors and asked them to send the article. Other criteria to include and exclude studies has been provided below. Furthermore, the process of systematic review of the literature is shown in Fig. 1. In some studies men and women with ID had participated in the study. We included these studies as well and extracted only the women's quotations.

According to PICOS, the related criteria to include studies were:

1. Population: Women with ID 16 years of age or older

2. Intervention: $\mathrm{N} / \mathrm{A}$

3. Comparison: $\mathrm{N} / \mathrm{A}$

4. Outcome: concerns and needs related to sexual health among women with ID

5. Study design: Qualitative studies

6. Published in English between January 1, 2000 and December 31, 2017

7. Full-text articles

The related criteria to exclude studies included:

1. Published before January 1, 2000 and after December 31, 2017
2. Abstracts, editorials, letter to editor, and comments

3. Protocols and method papers

4. Quantitative studies

5. Studies on individuals with ID under the age of 16

6. Grey literature (e.g. books, conference abstracts, theses, research reports, policy documents)

7. Non-English language studies

8. Studies that were not related to sexual health

\section{Search strategy}

This structured review was conducted using the guidelines of Preferred Reporting Items for Systematic Reviews and Meta-Analysis (PRISMA). The literature search included four bibliographic databases; "Web of Science", "PubMed", "Scopus" and "PsycINFO" involving all of the related studies from January 2000 to December 2017. Searches were conducted from June to August 2018. The studies were searched based on two main foci: (1) sexual health; and (2) women with ID. Our keywords to search articles were a combination of the words sex, sexual activity, sexual abuse, disability, intellectual disability, developmental disability and qualitative. Moreover, hand-searching reference lists of the included papers was applied to further identify articles which met

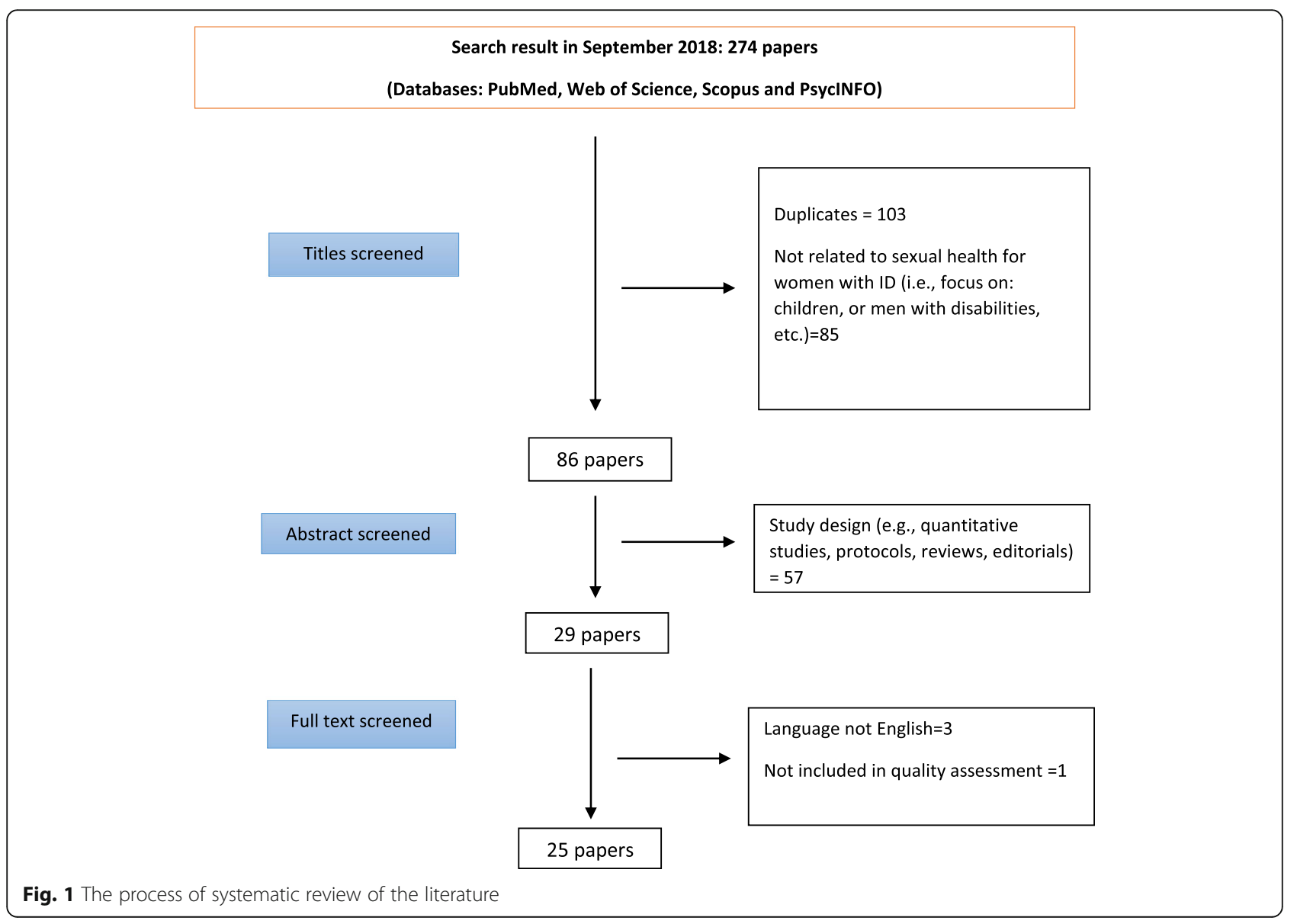


our inclusion criteria. The results of our search procedure in the four selected databases were 274 references which were exported to EndNote software version X7. The search strategies to find the relevant studies is shown in Table 1.

\section{Data extraction}

We set up a checklist in which the needed information such as authors, year, country, methodology, samples, study perspective, themes and main findings were extracted from the included studies. Searching and identifying the studies was executed by the corresponding author. The third and fourth authors of the present study (FD and AKK), summarized the findings and categorized the required information according to the prepared checklist. To ensure the validity of the checklist information, the corresponding author (SS) checked the accuracy of the extracted data. We identified all disagreements and resolved them by consensus after discussion. Also, we used MAXQDA version 11 to code and categorize qualitative data.

\section{Quality assessment}

Quality assessment of qualitative studies is a frequently debated topic in the literature. Contrary to qualitative studies, determining reliable criteria to assess the quality of qualitative studies may be a complicated problem for researchers. Given the aim of the study, we assessed the quality of the included studies using the Consolidated Criteria for Reporting Qualitative Research (COREQ) [24]. The quality assessment included the topics of study design, research framework, sampling method, gathering appropriate data according to aim of the study, data analysis approach, appropriate categorization of findings, reporting the findings and related data (photographs or quotes), etc. Two independent researchers who had no additional contribution to this study assessed the quality of included studies using a 5 point Likert scale. In order to apply the COREQ in the review process, we held two training sessions for the researchers. All items in the checklist were assessed and scored (from 1 to 5 ) by both researchers separately and the mean score was determined as the final score of the quality assessment. Therefore, in the final step of the review, we included studies that earned 3 points or higher.

\section{Results}

According to the stipulated research strategy, the corresponding author identified 274 records in the four databases, imported them into Endnote software and screened them according to the inclusion and exclusion criteria. The first step of screening was done according to the title of the studies and 197 articles were removed due to duplicates and the date of publication (before January 2000 or after December 2017). At the next step, the abstracts of the papers were studied and we excluded 47 additional papers due the method or study design (quantitative studies, review studies, letter to the editor, editorial, and protocols). At the final step of the screening process, we studied the full text of the remaining articles to extract their findings. In this step, we included 25 qualitative studies in the final step of the review process. Of these, three articles were unavailable in full text. The authors were contacted by email and they provided the articles. All 25 articles were categorized according to geographical area; 12 studies were conducted in Europe, 3 in Asia, 4 in the North America, 4 in Australia and 2 in Africa. Table 2 shows the characteristics of the reviewed studies.

Table 1 The search strategies ${ }^{a}$ to find the relevant studies

\begin{tabular}{|c|c|}
\hline Search Strategies & number \\
\hline \multicolumn{2}{|l|}{ Web of science } \\
\hline 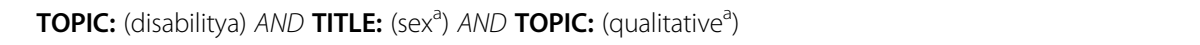 & 105 \\
\hline TITLE: (intellectual disability) AND TITLE: (sex ${ }^{a}$ ) AND TOPIC: (qualitative ${ }^{a}$ ) & 20 \\
\hline \multicolumn{2}{|l|}{ PubMed } \\
\hline ((intellectual disability[MeSH Terms]) AND sexual activity[MeSH Terms]) AND qualitative[Title/Abstract] & 14 \\
\hline ((intellectual disability[MeSH Terms]) AND sexual behavior[MeSH Terms]) AND qualitative[Title/Abstract] & 14 \\
\hline ((intellectual disability[MeSH Terms]) AND sexual abuse[MeSH Terms]) AND qualitative[Title/Abstract] & 4 \\
\hline \multicolumn{2}{|l|}{ Scopus } \\
\hline (TITLE (disability) AND TITLE (sex) AND TITLE-ABS-KEY (qualitative)) & 18 \\
\hline TITLE (intellectual AND disability) AND TITLE (sex) AND TITLE-ABS-KEY (qualitative) & 11 \\
\hline mainsubject(disability $\left.{ }^{a}\right)$ AND mainsubject(sex $\left.{ }^{a}\right)$ AND ab(qualitative ${ }^{a}$ ) & 62 \\
\hline ti(disability $\left.{ }^{a}\right)$ AND ti(sex $\left.{ }^{a}\right)$ AND ab(qualitative) & 26 \\
\hline Total & 274 \\
\hline
\end{tabular}




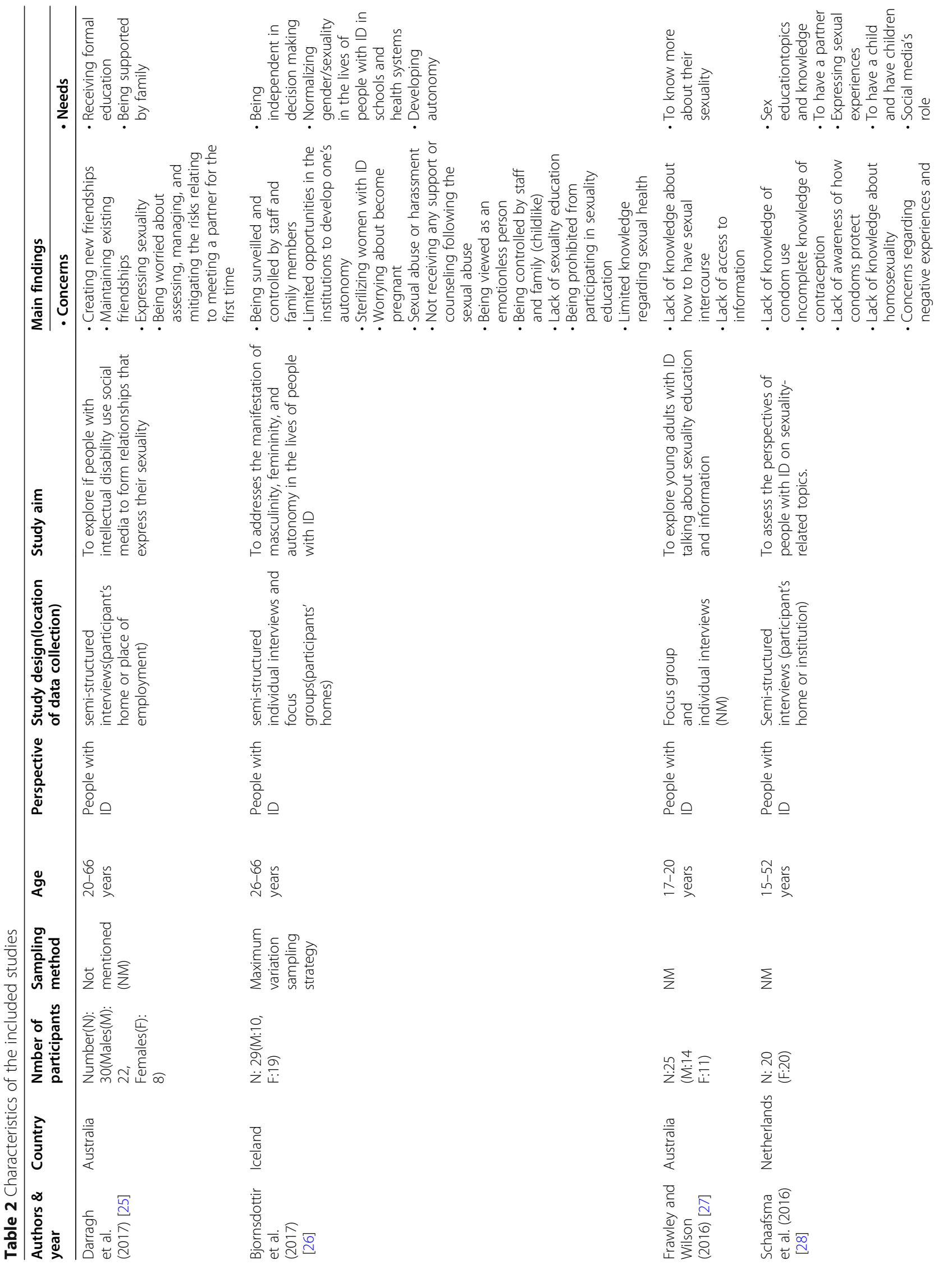




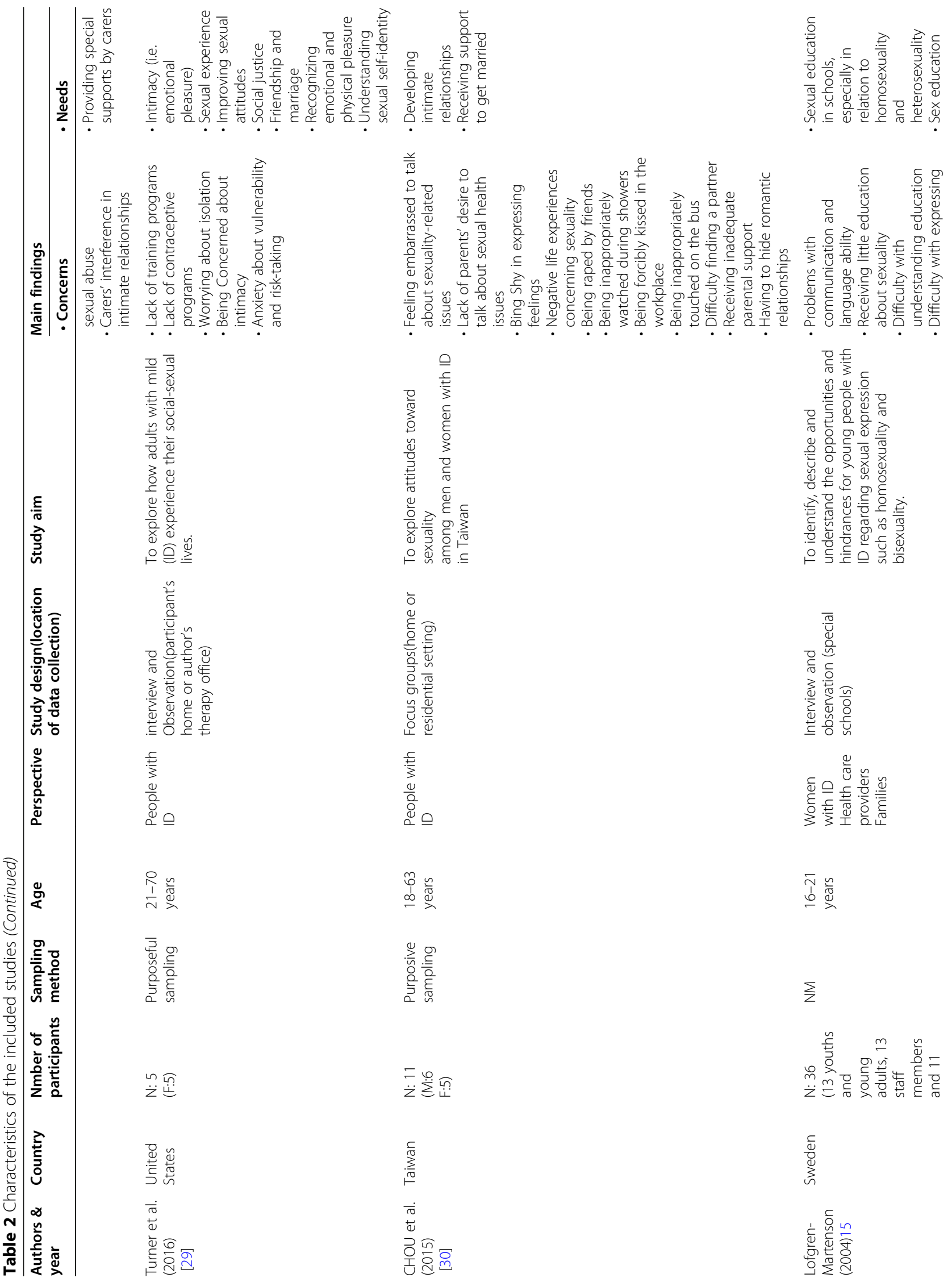




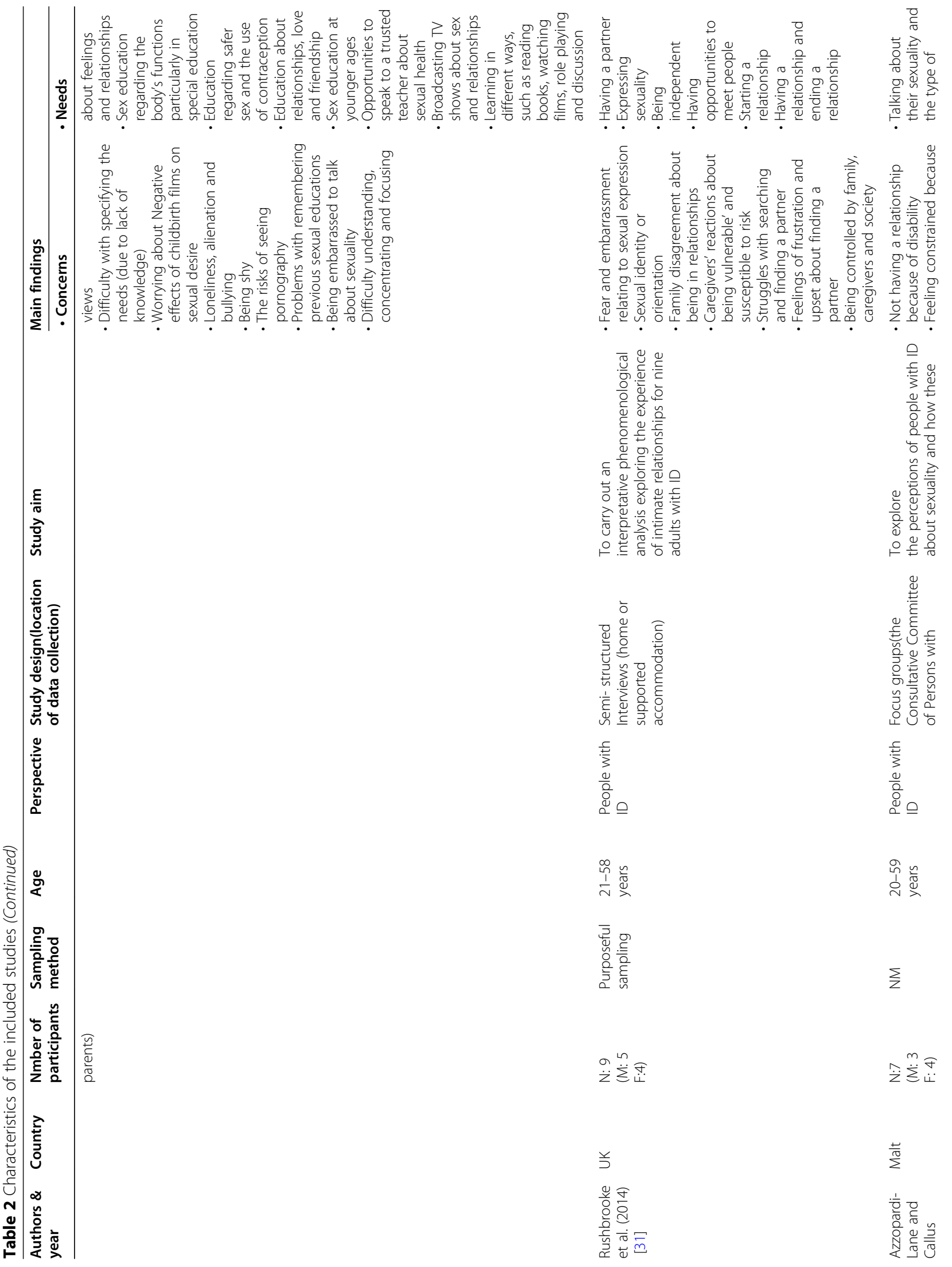




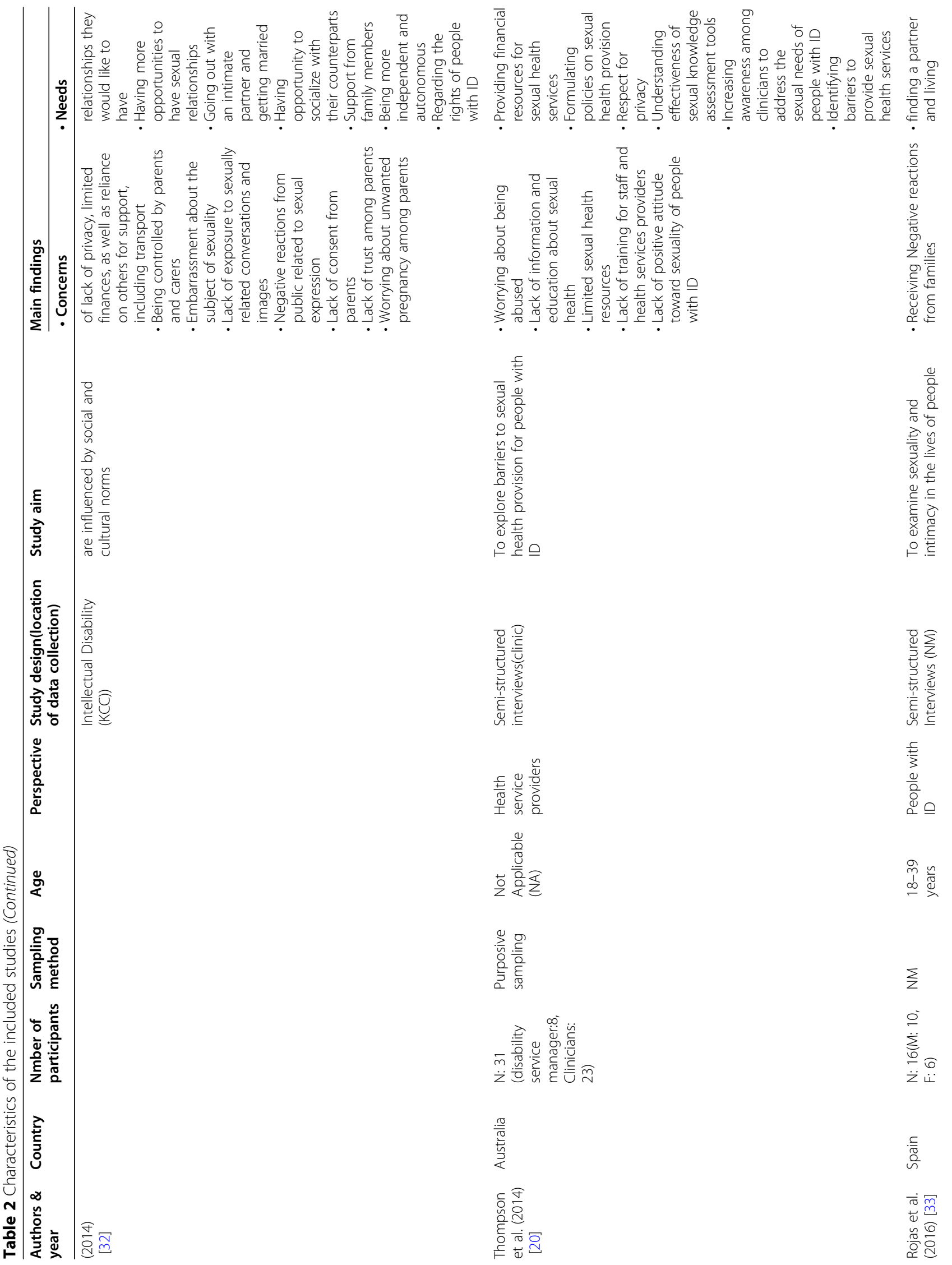




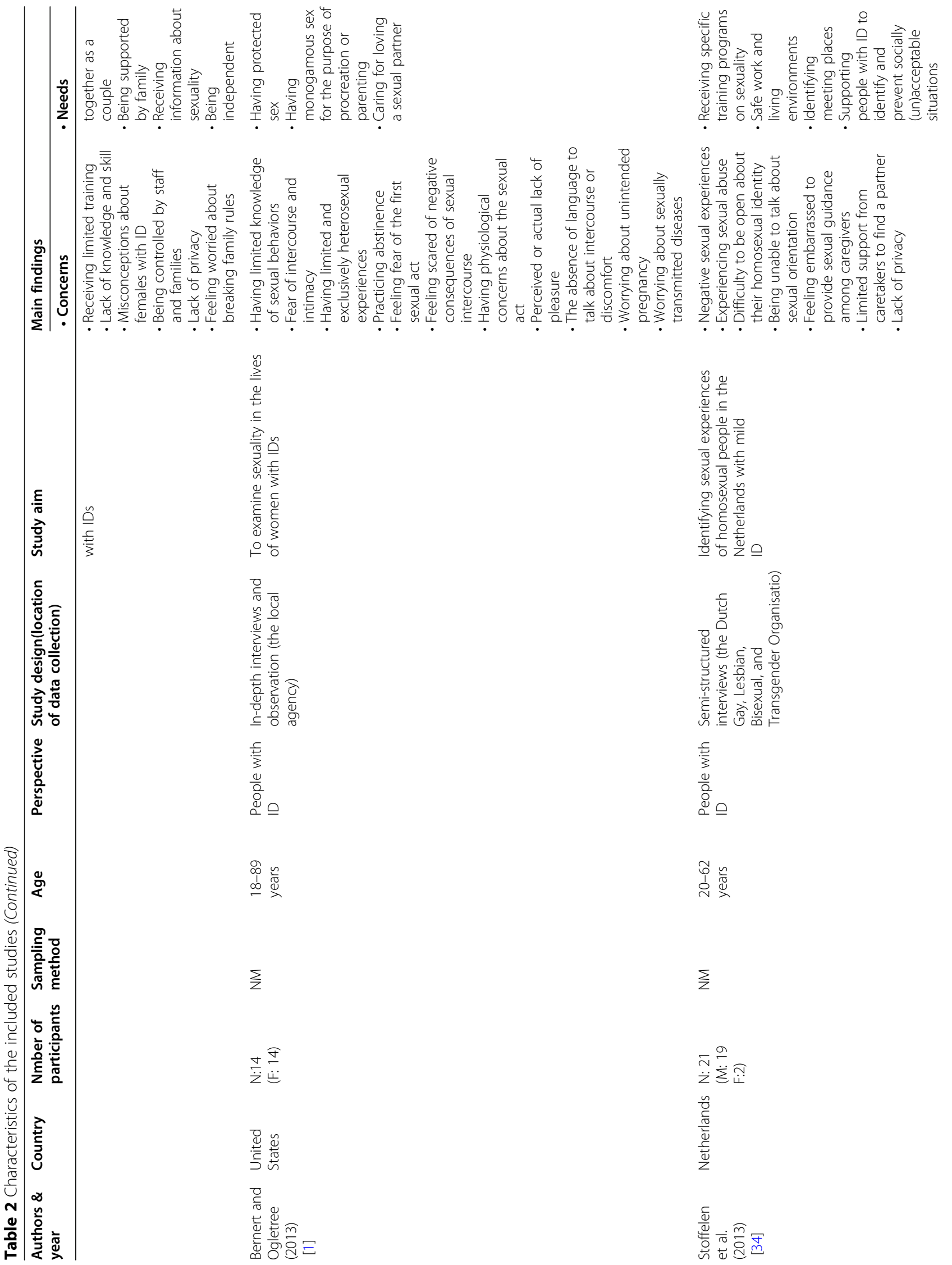




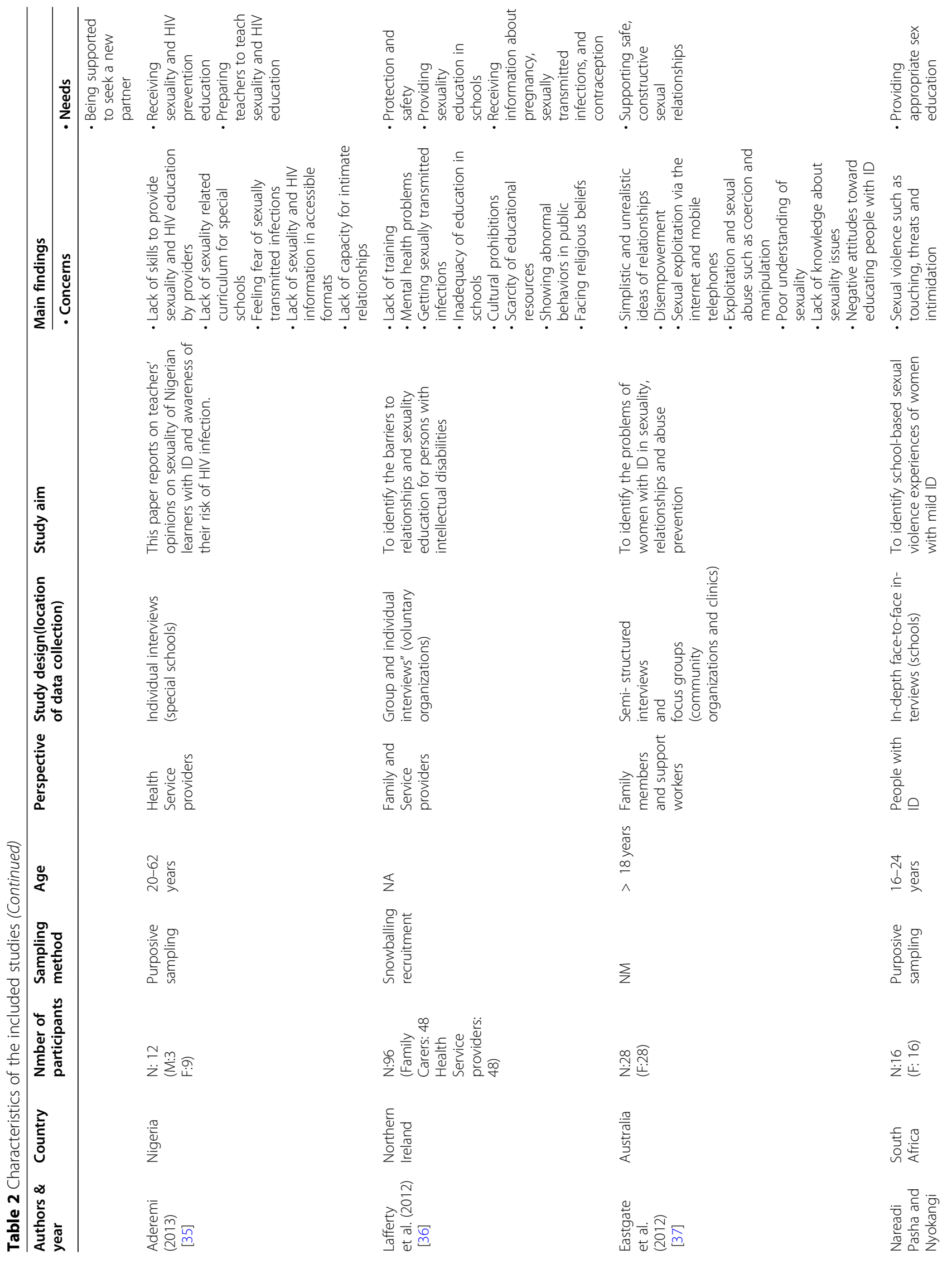




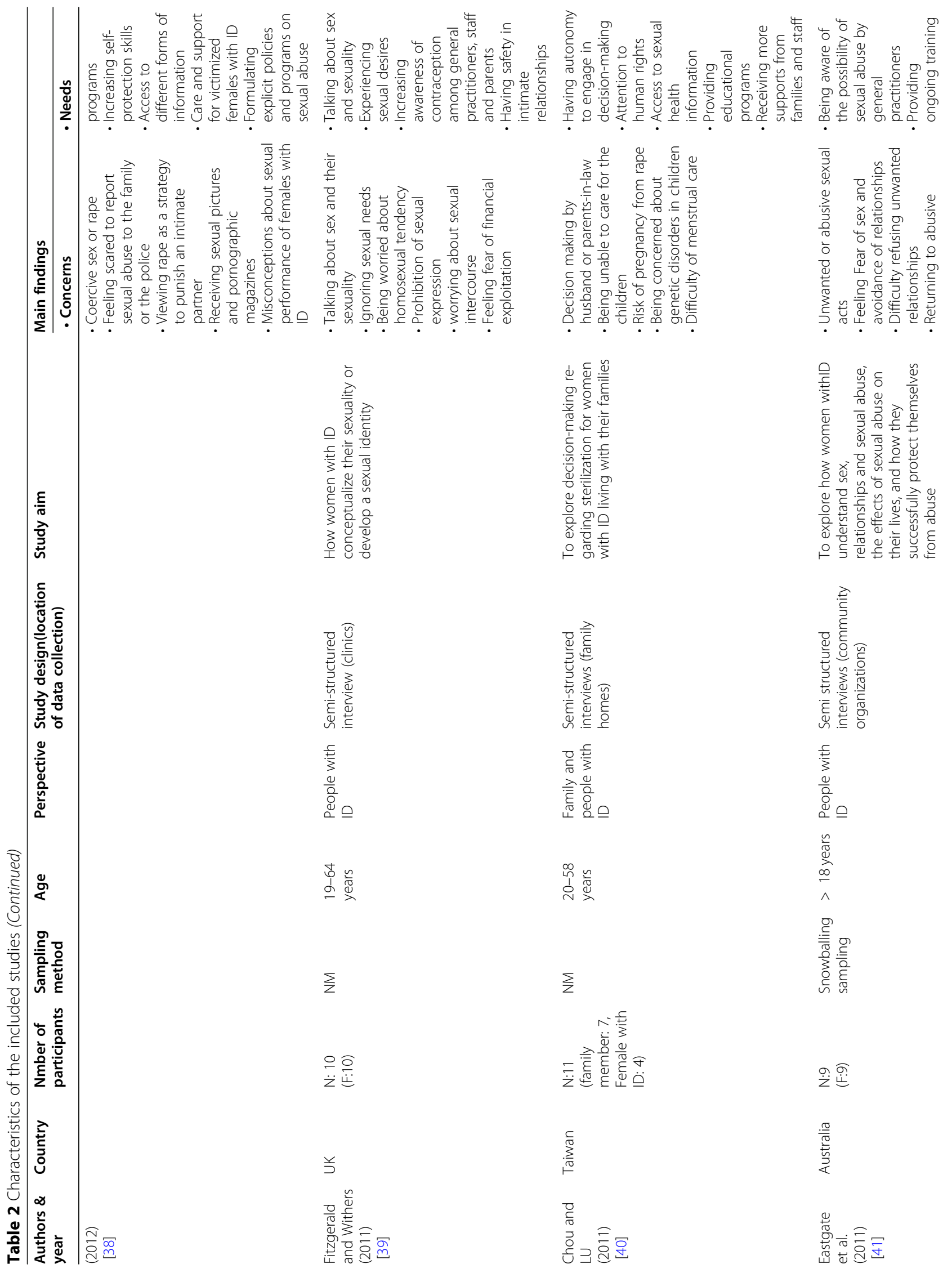




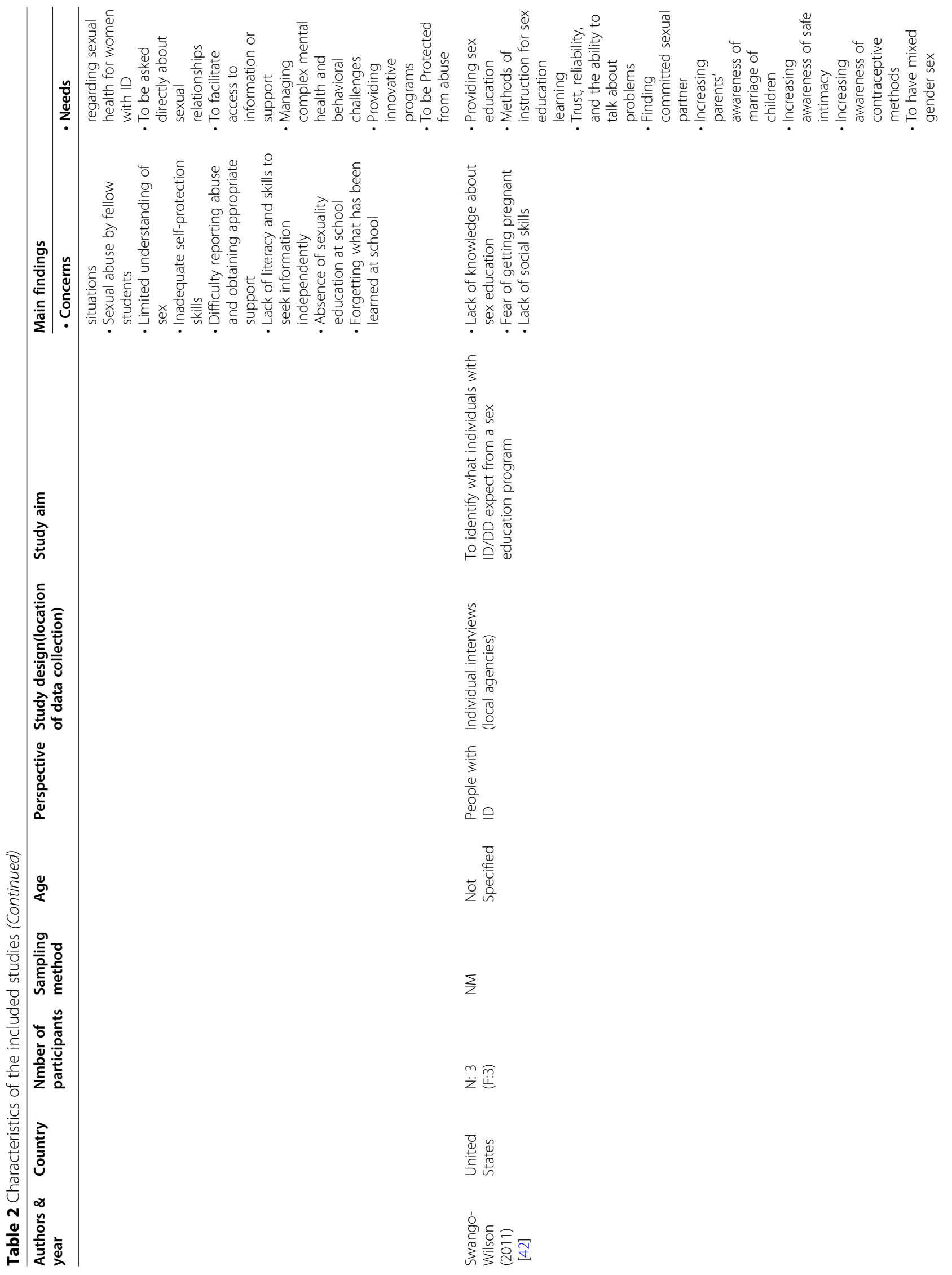




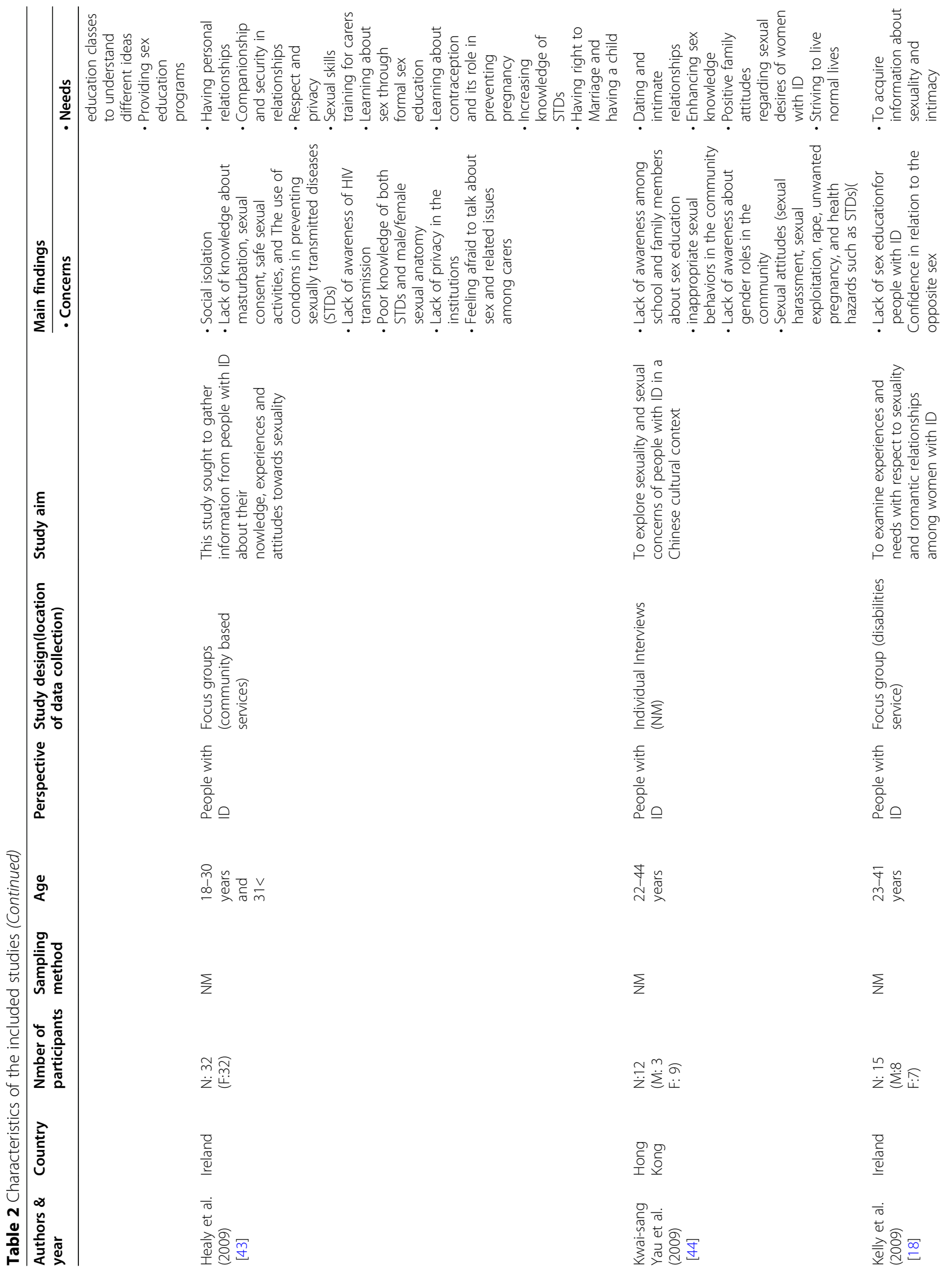




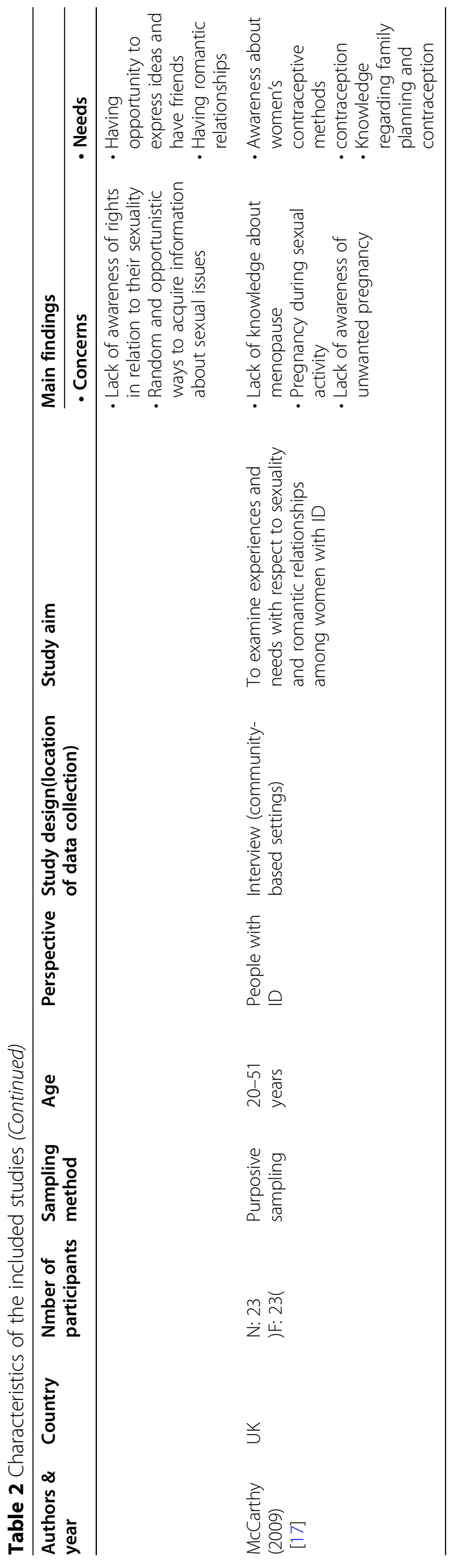


In the included studies, Participants were recruited from different settings such as censuses and surveys [40], community-based services (e.g. community learning disability services [31, 33, 43], clinics, organizations (e.g. voluntary organizations, organizations specialized in care for people with intellectual disabilities, the Dutch Gay, Lesbian, Bisexual, and Transgender Organization, voluntary organizations, special schools [34-36, 45], agency professionals [29], self-advocacy groups (e.g. Consultative Committee of Persons with Intellectual Disability) [32]. Some participants lived with their parents, some used residential services (i.e., group home), and some lived independently with support staff visiting for a number of hours a week [14, 15, 34, 44, 46].

Marital status for women with ID was various so that some of them were married, some were single, some reported being divorced, some were widowed, and some of them had biological children [32, 33, 45]. Some women with ID were employed during the study [1, 26, 41, 47]. Data collection was done in different setting such as participants' homes, offices, clinics, or residential settings $[14,20,26,28,45]$. Overall, different groups such as women with ID, parents, support workers [37], caregivers, teachers [35], social workers, educationalists, professionals (e.g. psychologist, occupational therapist) [36], and social care managers, nurses [36] participated in the included studies. Five studies reported the severity of ID so that they included women with mild or moderate ID in their studies $[17,29,30,34,38]$. Also, in most included studies, women with ID were eligible to participate in the study if they had a diagnosed intellectual disability. None of the included studies mentioned the cause of ID.

Women with ID mentioned different concerns in the included studies. We labeled each concern as a separate descriptive code. Codes were then used to summarize segments of data for each article, and we compared codes and sorted them into categories. The categorization of the concerns stated by participants is shown in Table 3.

\section{Knowledge and skill}

Across the studies, participants identified lack of sexual knowledge as a main barrier for women with ID to experience a healthy sexual relationship. Limited knowledge of contraceptive methods, sexual behaviours, sexual abuse, and the process of sexual intercourse and pregnancy were reported. In most studies, participants had a simplistic understanding of the process of sexual intercourse yet, in a limited few, women with ID possessed a sophisticated understanding of sexual intercourse. For example in Eastgate et al.'s study, some participants with mild ID had correct information about menses, time of ovulation and sperm motility. In others, participants lacked knowledge of the basics about males' bodies and some women with ID did not know how to

Table 3 The categorization of the concerns mentioned by participants in the included studies

\begin{tabular}{|c|c|c|}
\hline Category & Examples & $\begin{array}{l}\text { Number } \\
\text { of codes }\end{array}$ \\
\hline Being controlled & Being monitored by staff in instructions, lack of privacy & 6 \\
\hline Education & $\begin{array}{l}\text { Inadequacy of school-based sexuality education, being prohibited from participating in sexuality } \\
\text { education, lack of training programs for staff and families }\end{array}$ & 9 \\
\hline Knowledge and skills & $\begin{array}{l}\text { Limited knowledge of STDs, unwanted pregnancies, rights, genders roles, sexual identity, self-protection, } \\
\text { female and male anatomy, and contraceptive options }\end{array}$ & 24 \\
\hline Sexual abuse & $\begin{array}{l}\text { Sexual abuse in different ways (i.e., internet, manipulation, verbal) and in different settings such as public } \\
\text { places, difficulty reporting abuse, difficulty refusing unwanted sexual intercourse, sexual harassment, fear } \\
\text { of financial exploitation }\end{array}$ & 16 \\
\hline Information & Lack of literacy and needed skills to seek information independently, limited sexual health resources & 5 \\
\hline $\begin{array}{l}\text { Lack of support to find } \\
\text { a partner }\end{array}$ & $\begin{array}{l}\text { Limited support from caretakers, family disagreement, receiving less parental support, reliance on others } \\
\text { for supports, lack of trust among parents, lack of consent from parents, parents' concern about getting } \\
\text { pregnant, lack of support to engage in a relationship and access to a meeting place }\end{array}$ & 9 \\
\hline Shyness & Loving person in secret, being embarrassed to talk about sexual issues, shyness in expressing feelings & 10 \\
\hline Anxiety and fear & $\begin{array}{l}\text { Fear of sex, fear of first sexual act, concern about unwanted pregnancy, concern about isolation and } \\
\text { sterilization, psychological concerns, concern of negative sexual experiences, fear of STDs, }\end{array}$ & 26 \\
\hline Communication & Difficulty with expressing views and specifying needs, not being able to talk about sexuality & 6 \\
\hline Sociocultural barriers & $\begin{array}{l}\text { Social isolation, prohibition of sexual expression, negative reactions from staff, families and public, being } \\
\text { viewed as an emotionless, being sexually inactive, religious beliefs, }\end{array}$ & 9 \\
\hline Limited experiences & Lack of exposure to sexuality, Lack of pleasure & 3 \\
\hline Poor understanding & difficulty with understanding sexual orientation, societal norms, emotional feelings, sexual needs & 6 \\
\hline Intellectual capacities & $\begin{array}{l}\text { Forgetting what has been learned, not being in a relationship due to disability, inappropriate sexual } \\
\text { behaviors, problem with remembering issues }\end{array}$ & 6 \\
\hline
\end{tabular}


develop a sexual relationship with men [27]. For example, some participants had problems defining the progression from kissing or touching to a penetrative relationship.

\section{Education}

One of the major reasons for limited knowledge of sexual health can be attributed to the lack of access to comprehensive sexuality education. The review of findings indicated that the absence of sexuality education was a serious concern and detriment to the sexual health for women with ID. Some participants in the studies explained that they have not received any school-based sexuality education. For example, they were excluded from the classroom during sexuality education lessons. Women with ID in some schools were forbidden to talk about sexuality as it was considered an illegal act for them [41]. Some remarked that sexuality education was very general and thus they were not able to obtain complete information about their sexuality and bodies [26]. Also, participants noted that as adults, they need sexuality education to form romantic relationships and to become parents. Regarding the needs mentioned by women with ID, this education can be provided by knowledgeable parents, teachers and health professionals and consistently reinforced.

\section{Sociocultural barriers}

Some participants had to hide their sexual experiences and their consensual sexual contact in institutions or group homes because of prohibitive rules, negative attitudes towards their sexuality and lack of privacy. Stoffelen et al. found that women with ID desiring same-sex relationships experienced difficulty talking about their sexual orientation freely [34]. In Berenert et al.'s study, participants had a negative perception of sexual intercourse [1]. Engaging in some sexual acts was physically painful for them and the frequency of sexual intercourse was not a pleasant experience for some participants. For example one of the women described sex as "Sickening. That's how I think of it anymore. It's disgustingly gross, all [he] wanted was sex, but I didn't like havin' it all sex, all the time" (p. 245) [1]. Some participants were not curious about sex and felt regret having sex at younger ages because they were not ready to have a sexual relationship [1, 30, 48]. Some participants described sex as 'ugly, dirty, bad, disgusting, and displeasurable'(p. 245), and worried about their first sexual intercourse in the future, stating that it would be scary [1]. In addition, they were worried about the sexual health problems of their partner. Women with ID were scared of the negative consequences of sex like unintended pregnancy or sexually transmitted infections. Unwanted pregnancies in sexual intercourse between people with ID was one of the major concerns of families $[37,49,50]$.

\section{Being controlled}

Many of the women with ID noted that they had little control over their lives. Lack of autonomy caused limited opportunities for women with ID to form friendships and romantic relationships. Women with ID living in institutions had to behave according to the institution's rules. In Kelly et al.'s study women with ID noted that their relationships with partners are controlled by staff in the institutions and thought that they were not trusted to have a healthy romantic relationship [18]. Also, in Bjornsdottir et al.'s study, which included both male and female participants, women seemed to be controlled by families and staff for sexual activities, fertility and sterilizations at a greater degree than males [26]. For example one of participants in the included studies stated that "I wasn't allowed to move to the group home unless I had the sterilization" (p. 304). Not only were the participants' decisions and choices about an intimate relationship restricted by families or caregivers but also the lack of services and stigmas perpetuated by society delimited their options. They noted that people think that they cannot have a sexual or friendly relationship because of ID [31]. Also, they mentioned that being controlled by families has affected the quality and stability of their relationships with their boyfriends. This problem would lead to dissatisfaction among women with ID so that they were not able to express their sexuality openly. Also, Rushbrooke and colleagues identified some internal and external factors contributing to a lack of control by women with ID [31]. Internal factors included being passive in relationships, perceived ability to cope, and insufficient opportunities to create social contacts and spend time with partners. External factors were categorized as the influence of others and the impact of policy. The participants stated that being controlled along with negative experiences caused a lack of confidence and anxiety.

\section{Lack of support to find an intimate partner}

One of the important needs of women with ID to have a safe sexual relationship was finding an intimate partner. In Stoffelen et al.'s study, although the participants reported they desired a partner, they did not know how to find one [34]. They need support to seek a partner but their caregivers did not know how to provide proper support. Women with ID need opportunities and venues to socialize to provide opportunities to meet an appropriate partner. In Chou et al.'s study, participants mentioned that they were attracted to and had feelings for their teachers or male relatives in secret. For example one of the women with ID stated that "I have liked my 
teacher at the gas station (workplace) for two years. But I am shy to tell him" (p.672) [30]. Furthermore, women with ID experienced problems with ending an intimate relationship when they did have a partner. Some women with ID reported that they have boyfriends but they need supports to find a place to make love [34]. Additionally, discrimination in providing supports was one of the concerns mentioned by women with ID. They noted that men with ID faced less barrier to get married and their families agree to the marriage of their children [31].

\section{Sexual abuse}

In the included studies, many of the participants had stated negative experiences concerning sexuality in their lives. Sexual abuse by friends and colleagues frequently was reported by women with ID. Being forcibly kissed, viewed or touched inappropriately, and raped were experiences reported by women with ID [30]. Sexual abuse usually happened in public places like institutions, schools, public transportation, and workplaces [30, 31, 41]. When reporting sexual abuse to police or other authorities, women with ID encountered negative reactions from their families or caregivers. Some of the interviewees had experienced sexual abuse beginning as involuntary sterilization during their adolescence.

Vulnerability was one of the considerable concerns mentioned by women with ID or their caregivers. In some studies, the limited knowledge of and the lack of skills needed for healthy sexual contacts would make them especially vulnerable to sexual abuse. Eastgate found that disempowerment can increase the probability of sexual exploitation. For instance the mother of a woman with IDs stated that "I think she would just want to make that person happy and do whatever they want her to do ... she does things to please people"(p.136) [37]. In the included studies, a variety of unwanted actions such as manipulation and coercion were mentioned as sexual abuse by women with ID. Some studies reported that emotional relationships that occur in secret may increase the risk of sexual abuse for women with ID. But the findings of Schaafsma et al. show that public places like schools and institutions can leave women with ID more vulnerable to different types of physical and verbal abuse. In this particular study, women with ID who had experienced sexual abuse stated that they were targeted because they had been sterilized and thus could not become pregnant as a result of the abuse [28]. As a result, the experience of sexual abuse would lead to fear of new emotional relationships among participants in the future.

\section{Communication}

Due to a speech and cognitive impairments, women with ID faced problems to talk about sexuality issues. They were not able to explore and specify their sexual needs. Some participants had problems recalling previous learning about sexual topics [41]. Cognitive challenges affect social interactions among women with ID. Some women with ID reported that they were not able to express their feelings and sexual needs [45]. In the included studies, some participants noted that women with lower intellectual functioning had less of a chance to create and maintain an intimate relationship [35, 51].

\section{Shyness}

The feeling of embarrassment was one of the considerable problems of women with ID to find a partner and create an intimate relationship. The attribute would affect sexual expression among women with ID. In some studies, participants were shy to discuss about topics like masturbation, sexual intercourse and sterilization [30]. Some interviewees with ID preferred to attend classes with a familiar teacher or only with a woman to receive sex education. In Löfgren-Martenson's study, one of the participant noted that she never talk to anyone about sexuality and this was a painful problem for her [45]. In addition, some studies indicated that some parents and carers are shy to provide sexual guidance for women with ID [31, 32, 34].

\section{Information}

Lack of information in relation to sexuality was one the concerns mentioned by women with ID in the included studies. Because of limited intellectual capacities they faced barriers to seek the needed information. Also, lack of literacy and the communication skills such as listening, eye contact and empathy would exacerbate their access to sexual health information [41]. They received their information randomly through their friends or relatives [18]. Thompson et al. found that limited sexual health resources was one of the major barriers to access the needed information among women with ID [20].

\section{Discussion}

The aim of the systematic review study was to identify sexual health needs experienced by women with ID worldwide. The findings of the study indicated that women with ID have sexual desires and need specific supports to make a healthy sexual relationship. Lack of education was a major problem stated by participants in the included studies. They need to be engaged in sexuality education programs with trusted caregivers to improve their knowledge about sexual health. Sexuality education programs need to be adapted to the needs of women with ID. Studies show that sex education interventions can have a positive impact on knowledge, selfprotection, empowerment, and decision making for women with ID [47, 52]. Sexuality education should 
cover different dimensions including contraceptive methods, self-protection skills, sexual consent, and STI. It is important to note that caregivers and family members can play a considerable role in sexual health education. Women with ID often have a poor understanding of sexual knowledge that can lead to inappropriate behaviors and increase the likelihood of sexual abuse [37, 43, 53]. Learning how to meet partners, engage in healthy relationships and appropriately express romantic feelings could help to minimize these negative outcomes [18, 30,31].

In the studies reviewed, some women with ID reported being forbidden to participate in sexual education in schools [26]. Cultural prohibitions sometimes limit access to sexual care and increase unmet sexual health needs for women with ID [36]. The findings reveal that sexuality issues are a taboo subject increasing the challenges to seeking information.

Finding an intimate partner is a notable issue mentioned by women with ID in the included studies. Although the studies showed that women with ID would like to engage in romantic relationships, participants reported difficulty expressing their feelings. Lack of confidence, shyness, families' dissatisfaction, and lack of a meeting place were leading factors that affect their relationships. Studies reveal that parents have more conservative attitudes toward sexual activities in women with ID $[54,55]$. In the Swango-Wilson's study, some participants mentioned that commitment is an important issue in developing a lasting relationship with men but some of them were not ready to make a commitment to start a family [53]. According to the above-mentioned studies, women with ID should receive more support from their families and caregivers to develop or end an intimate relationship. Participating in educational and supportive programs can help promote constructive options to develop healthy relationships. Families need to provide more opportunities for women with ID to express their feelings. Respecting the feelings and desires of women with ID should be considered by families and policymakers. Also, cultural barriers like discriminations and misconceptions need to receive more attention by researchers especially in countries with more religious restrictions.

The present review indicated that women with ID have little control over their lives. They were not able to make independent decisions about their sexual lives. In residential facilities, women's fertility is controlled by families and governmental policies. This study indicates that many women with ID do not have access to necessary information to develop autonomy in their private lives [46]. Studies suggest that families should act as a facilitator and provide needed information for women with ID so that they can make their own choices and develop their autonomy $[46,56,57]$. However, some studies note that families cannot provide sexuality education for women with ID due to sociocultural barriers. Hence sex education approaches need to occur in multiple venues, including schools and healthcare arenas. For example, the findings of Kwai-sang Yau et al. indicate that some parents forbid their children from seeing passionate or erotic scenes in movies by turning the television off [44]. It seems that parents and carers can have an informative discussion with the adult with ID about passionate scenes instead of forbidding them.

In addition, because of cognitive limitations, women with ID are more vulnerable to risks like sexual exploitation, unwanted pregnancy and STI than their nondisabled peers. This issue can be investigated from different dimensions. Self-protection skills such as consent to sex and reporting the sexually abusive incident should be taught by public or non-governmental organizations (NGOs) for women with ID [58]. In the included studies, women with ID had experienced sexual abuse in different contexts. Chamberlain et al. and Elikins et al. report that a $25 \%$ and a $27 \%$ prevalence of sexual abuse in women with ID in the community and outpatient sections.

Finally, some women with ID talked about their desires for intimate relationships with other women. Specific difficulties such as stigma, lack of training, negative social attitudes, and lack of support by families were experienced by lesbians with ID. Regarding Article 12 of the United Nation Convention on the Rights of People with Disabilities, respecting the decisions of women with ID can be the first key step to address this challenge [59]. Also, cultural provisions and religious constraints are two notable barriers to the sexual expression of homosexual people with ID that should be considered in future research and policy endeavors.

\section{Limitations}

Our study face some limitations. This study only represented the sexual health concerns of women with ID, while females with ID aged under 16 years and other women with disabilities (e.g. hearing impairments, physical disabilities, mental disorders and vision loss) may have different concerns and needs that can be investigated in future studies. We did not include gray literature and non-English language articles which in turn may affect the findings of the present study. Our study did not examine the sexual health concerns in men with ID. Men with ID may have complex and unique needs and concerns due to different psychological, biological, cultural and environmental factors that can be investigated in future studies $[8,60]$. To look for more relevant articles, and regarding that the databases had different features to search data, we used different search terms 
to find the included articles. Furthermore, it should be noted that we included papers published from January 2000 to December 2017. We think that the coronavirus pandemic was one of the main reasons for the delay in the peer review process.

\section{Implication for practice and/or policy}

Participating in educational and supportive programs can help promote constructive options to develop healthy relationships for women with ID. Families need to provide more opportunities for women with ID to express their feelings. Families should act as a facilitator and provide needed information for women with ID so that they can make their own choices and develop their autonomy. Respecting the feelings and desires of women with ID should be considered by families and policymakers. Cultural provisions and religious constraints are notable barriers to the sexual expression of homosexual people with ID that should be considered in future research and policy endeavors.

\section{Conclusion}

In general, participants with ID mentioned various concerns such as lack of sexual experience, negative experiences, lack of understanding, problem with finding a right partner, lack of access to information, sexual abuse, and limited knowledge of sexual behaviors. The findings indicate that women with ID need to be provided with school-based sexuality education tailored to the level of understanding needed to attain the requisite knowledge to form relationships, understand sexual and romantic relationships, and practice safe sex when they choose this option. Families along with education and healthcare systems should provide opportunities for women with ID to talk about their sexual needs and make their own choices.

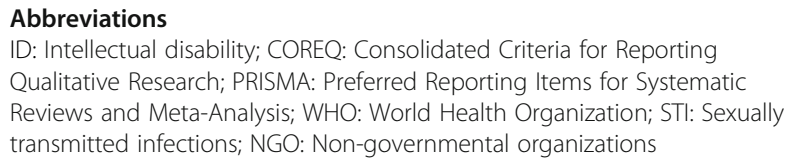

\section{Acknowledgements}

N/A

\section{Authors' contributions}

BKM: Contributed in the design of the work, analysis and interpretation of the results, writing and revising the full manuscript; MB: Contributed in analyzing the data, writing and revising the full manuscript,; FD: Contributed in the design of the work, collecting and analyzing the data, and revising the manuscript; AKK: Contributed in the design of the work, collecting and analyzing the data and interpreting the results; MS: Contributed in the design of the work, collecting and analyzing the data; SS: Contributed in design of the work, analyzing the data and interpreting the results, writing and revising the full manuscript; All authors read and approved the submitted version of the manuscript. Also, all authors agreed both to be personally accountable for the author's own contributions and to ensure that questions related to the accuracy or integrity of any part of the work are appropriately investigated, resolved, and the resolution documented in the literature.

\section{Funding}

The present study was funded by the Asadabad University of Medical Sciences. The funder had no role beyond the funding call in the design of the study, data collection, analysis, data interpretation, or writing the manuscript.

\section{Availability of data and materials}

Dr. Soltani have full access to all the data in the study and takes full responsibility for the integrity of the data and the accuracy of the data analysis.

\section{Declarations}

Ethics approval and consent to participate

The study was approved by the ethics committee of Asadabad University of Medical Sciences (the code of ethics: IR.ASAUMS.REC.1399.006),

\section{Consent for publication}

Not applicable.

\section{Competing interests}

The authors declare no conflict of interest.

\section{Author details}

${ }^{1}$ Research Center for Environmental Determinants of Health, Health Institute, Kermanshah University of Medical Sciences, Kermanshah, Iran. ${ }^{2}$ School of Social Welfare, Stony Brook University, New York, USA. ${ }^{3}$ Department of Public Health, Asadabad School of Medical Sciences, Asadabad, Iran.

Received: 28 July 2020 Accepted: 15 October 2021

Published online: 30 October 2021

\section{References}

1. Bernert DJ, Ogletree RJ. Women with intellectual disabilities talk about their perceptions of sex. J Intellect Disabil Res. 2013;57(3):240-9. https://doi.org/1 $0.1111 / j .1365-2788.2011 .01529 . x$.

2. Ivankovich MB, Fenton KA, Douglas JM Jr. Considerations for national public health leadership in advancing sexual health. Public Health Rep. 2013; 128(Suppl 1(Suppl 1)):102-10.

3. Friedman HS. The disorders: specialty articles from the encyclopedia of mental health: Elsevier; 2001

4. Greenwood NW, Wilkinson J. Sexual and reproductive health care for women with intellectual disabilities: a primary care perspective. Int J Family Med. 2013;2013:642472.

5. Borawska-Charko M, Rohleder P, Finlay WML. The sexual health knowledge of people with intellectual disabilities: a review. Sex Res Soc Policy. 2017; 14(4):393-409. https://doi.org/10.1007/s13178-016-0267-4.

6. Eastgate $\mathrm{G}$. Sexual health for people with intellectual disability. Salud Publica Mex. 2008;50(Suppl 2):s255-9. https://doi.org/10.1590/S0036-36342 008000800019

7. Murphy GH, O'Callaghan A. Capacity of adults with intellectual disabilities to consent to sexual relationships. Psychol Med. 2004;34(7):1347-57. https:// doi.org/10.1017/S0033291704001941.

8. Servais L. Sexual health care in persons with intellectual disabilities. Ment Retard Dev Disabil Res Rev. 2006;12(1):48-56. https://doi.org/10.1002/mrdd.2 0093.

9. Eastgate G. Sex and intellectual disability dealing with sexual health issues. Aust Fam Physician. 2011:40(4):188-91.

10. Stoffelen JMT, Schaafsma D, Kok G, Curfs LMG. Sexual Health of People With an Intellectual Disability. In: Fisher $\mathrm{MH}$, editor. Identifying and Addressing the Social Issues Experienced by Individuals with Idd. Int Rev Res Dev Disabil. 2017;52:201-37.

11. Cambridge P. Challenges for safer sex education and HIV prevention in services for people with intellectual disabilities in Britain. Health Promot Int. 1998;13(1):67-74. https://doi.org/10.1093/heapro/13.1.67.

12. O'Callaghan AC, Murphy GH. Sexual relationships in adults with intellectual disabilities: understanding the law. J Intellect Disabil Res. 2007:51(3):197-206. https://doi.org/10.1111/j.1365-2788.2006.00857.x. 
13. Leutar Z, Mihoković M. Level of knowledge about sexuality of people with mental disabilities. Sex Disabil. 2007;25(3):93-109. https://doi.org/10.1007/ s11195-007-9046-8.

14. McCabe MP. Sexual knowledge, experience and feelings among people with disability. Sex Disabil. 1999;17(2):157-70. https://doi.org/10.1023/A:1 021476418440.

15. Löfgren-Mårtenson L. "May I?" about sexuality and love in the new generation with intellectual disabilities. Sex Disabil. 2004;22(3):197-207. https://doi.org/10.1023/B:SEDI.0000039062.73691.cb.

16. Esmail S, Darry K, Walter A, Knupp H. Attitudes and perceptions towards disability and sexuality. Disabil Rehabil. 2010;32(14):1148-55. https://doi. org/10.3109/09638280903419277.

17. McCarthy M. Contraception and women with intellectual disabilities. J Appl Res Intellect Disabil. 2009;22(4):363-9. https://doi.org/10.1111/j.1468-3148.2 008.00464.x.

18. Kelly G, Crowley H, Hamilton C. Rights, sexuality and relationships in Ireland: IIt'd be nice to be kind of trusted. Br J Learn Disabil. 2009;37(4):308-15. https://doi.org/10.1111/j.1468-3156.2009.00587.x.

19. Fraley SS, Mona LR, Theodore PS. The sexual lives of lesbian, gay, and bisexual people with disabilities: psychological perspectives. Sex Res Soc Policy. 2007:4(1):15-26. https://doi.org/10.1525/srsp.2007.4.1.15.

20. Thompson VR, Stancliffe RJ, Broom A, Wilson NJ. Barriers to sexual health provision for people with intellectual disability: a disability service provider and clinician perspective. J Intellect Develop Disabil. 2014;39(2):137-46. https://doi.org/10.3109/13668250.2014.898742.

21. Cobigo V, Ouellette-Kuntz H, Balogh R, Leung F, Lin E, Lunsky Y. Are cervical and breast cancer screening programmes equitable? The case of women with intellectual and developmental disabilities. J Intellect Disabil Res. 2013; 57(5):478-88. https://doi.org/10.1111/jir.12035.

22. Wilkinson JE, Culpepper L, Cerreto M. Screening tests for adults with intellectual disabilities. J Am Board Fam Med. 2007;20(4):399-407. https:// doi.org/10.3122/jabfm.2007.04.060210.

23. Pathak V, Jena B, Kalra S. Qualitative research. Perspect Clin Res. 2013;4(3): 192.

24. Tong A, Sainsbury P, Craig J. Consolidated criteria for reporting qualitative research (COREQ): a 32-item checklist for interviews and focus groups. Int Qual Health Care. 2007;19(6):349-57. https://doi.org/10.1093/intqhc/ mzm042.

25. Darragh J, Reynolds L, Ellison C, Bellon M. Let's talk about sex: How people with intellectual disability in Australia engage with online social media and intimate relationships. Cyberpsychology: Journal ofPsychosocial Research on Cyberspace. 2017;11(1):Article 9. https://doi.org/10.5817/CP2017-1-9.

26. Björnsdóttir K, Stefánsdóttir Á, Stefánsdóttir GV. People with intellectual disabilities negotiate autonomy, Gender and Sexuality. Sex Disabil. 2017; 35(3):295-311. https://doi.org/10.1007/s11195-017-9492-x.

27. Frawley P, Wilson NJ. Young people with intellectual disability talking about sexuality education and information. Sex Disabil. 2016;34(4):469-84. https:// doi.org/10.1007/s11195-016-9460-x

28. Schaafsma D, Kok G, Stoffelen JMT, Curfs LMG. People with intellectual disabilities talk about sexuality: implications for the development of sex education. Sex Disabil. 2017;35(1):21-38. https://doi.org/10.1007/s11195-0169466-4.

29. Turner GW, Crane B. Pleasure is paramount: adults with intellectual disabilities discuss sensuality and intimacy. Sexualities. 2016;19(5-6):677-97. https://doi.org/10.1177/1363460715620573.

30. Chou YC, Lu ZY, Pu CY. Attitudes toward male and female sexuality among men and women with intellectual disabilities. Women Health. 2015:55(6): 663-78. https://doi.org/10.1080/03630242.2015.1039183.

31. Rushbrooke E, Murray C, Townsend S. The experiences of intimate relationships by people with intellectual disabilities: a qualitative study. J App Res Intellect Disabil. 2014;27(6):531-41. https://doi.org/10.1111/jar.12091.

32. Azzopardi-Lane C, Callus AM. Constructing sexual identities: people with intellectual disability talking about sexuality. Br J Learn Disabil. 2015;43(1): 32-7.

33. Rojas S, Haya I, Lazaro-Visa S. My great hope in life is to have a house, a family and a daughter': relationships and sexuality in intellectually disabled people. $\mathrm{Br}$ J Learn Disabil. 2016;44(1):56-62. https://doi.org/10.1111/bld.12110.

34. Stoffelen J, Kok G, Hospers H, Curfs LMG. Homosexuality among people with a mild intellectual disability: an explorative study on the lived experiences of homosexual people in the Netherlands with a mild intellectual disability. J Intellect Disabil Res. 2013;57(3):257-67. https://doi. org/10.1111/j.1365-2788.2011.01532.x.

35. Aderemi TJ. Teachers' perspectives on sexuality and sexuality education of learners with intellectual disabilities in Nigeria. Sex Disabil. 2014;32(3):24758. https://doi.org/10.1007/s11195-013-9307-7.

36. Lafferty A, McConkey R, Simpson A. Reducing the barriers to relationships and sexuality education for persons with intellectual disabilities. J Intellect Disabil. 2012;16(1):29-43. https://doi.org/10.1177/1744629512438034.

37. Eastgate G, Scheermeyer E, van Driel ML, Lennox N. Intellectual disability, sexuality and sexual abuse prevention - a study of family members and support workers. Aust Fam Physician. 2012;41(3):135-9.

38. Phasha TN, Nyokangi D. School-based sexual violence among female learners with mild intellectual disability in South Africa. Violence Against Women. 2012;18(3):309-21. https://doi.org/10.1177/1077801212444578.

39. Fitzgerald C, Withers P. 'I don't know what a proper woman means': what women with intellectual disabilities think about sex, sexuality and themselves. Br J Learn Disabil. 2013;41(1):5-12. https://doi.org/10.1111/j.14 68-3156.2011.00715.x.

40. Chou YC, Lu ZY. Deciding about sterilisation: perspectives from women with an intellectual disability and their families in Taiwan. J Intellect Disabil Res. 2011;55(1):63-74. https://doi.org/10.1111/j.1365-2788.2010.01347.x.

41. Eastgate $G$, Van Driel ML, Lennox NG, Scheermeyer E. Women with intellectual disabilities--a study of sexuality, sexual abuse and protection skills. Aust Fam Physician. 2011;40(4):226-30.

42. Wilson NJ, Frawley P. Transition staff discuss sex education and support for young men and women with intellectual and developmental disability. J Intellect Develop Disabil. 2016;41(3):209-21. https://doi.org/10.3109/136682 50.2016.1162771.

43. Healy E, McGuire B, Evans D, Carley S. Sexuality and personal relationships for people with an intellectual disability. Part I: service-user perspectives. J Intellect Disabil Res. 2009;53(11):905-12. https://doi.org/10.1111/j.1365-2 788.2009.01203.x

44. Yau MK-s, Ng GS-m, Lau DY-k, Chan KS, Chan JS-k. Exploring sexuality and sexual concerns of adult persons with intellectual disability in a cultural context. Br J Dev Disabil. 2009;55(109):97-108. https://doi.org/10.1179/ 096979509799103089

45. Lofgren-Martenson L. "I want to do it right!" a pilot study of Swedish sex education and young people with intellectual disabilities. Sex Disabil. 2012; 30(2):209-25. https://doi.org/10.1007/s11195-011-9239-z.

46. Bjornsdottir K, Stefansdottir GV, Stefansdottir A. It's my life': autonomy and people with intellectual disabilities. J Intellect Disabil. 2015;19(1):5-21. https://doi.org/10.1177/1744629514564691.

47. Ballan MS, Freyer MB. The sexuality of young women with intellectual and developmental disabilities: a neglected focus in the American foster care system. Disabil Health J. 2017;10(3):371-5. https://doi.org/10.1016/j.dhjo.201 7.02.005.

48. Hoglund B, Larsson M. Struggling for motherhood with an intellectual disability--a qualitative study of women's experiences in Sweden. Midwifery. 2013;29(6):698-704. https://doi.org/10.1016/j.midw.2012.06.014.

49. Stinson J, Christian L, Dotson LA. Overcoming barriers to the sexual expression of women with developmental disabilities. Res Pract Persons Severe Disabil. 2002;27(1):18-26. https://doi.org/10.2511/rpsd.27.1.18.

50. Maia ACB. Sexuality experience as from report of people with intellectual disability. Psicol Estud. 2016;21(1):77-88. https://doi.org/10.4025/psicolestud. v21i1.29480.

51. Finlay WML, Rohleder P, Taylor N, Culfear H. 'Understanding' as a practical issue in sexual health education for people with intellectual disabilities: a study using two qualitative methods. Health Psychol. 2015;34(4):328-38. https://doi.org/10.1037/hea0000128.

52. Bruder C, Kroese B. The efficacy of interventions designed to prevent and protect people with intellectual disabilities from sexual abuse: a review of the literature. 2005;7(2):13-27. https://doi.org/10.1108/14668203200500009.

53. Swango-Wilson A. Meaningful sex education programs for individuals with intellectual/ developmental disabilities. Sex Disabil. 2011;29(2):113-8. https:// doi.org/10.1007/s11195-010-9168-2.

54. Cuskelly $M, R J J O l ~ B$, disability D. Attitudes towards the sexuality of adults with an intellectual disability: parents, support staff, and a community sample. 2004;29(3):255-64. https://doi.org/10.1080/13668250412331285136.

55. Chen Y, MJJOSE C. A study of parents' marital attitude for their children with intellectual disabilities in the high schools. 2011:34:57-100. 
56. Stefánsdóttir GV, Björnsdóttir K, Stefánsdóttir Á. Autonomy and people with intellectual disabilities who require more intensive support; 2018.

57. Devi N. Supported decision-making and personal autonomy for persons with intellectual disabilities: article 12 of the UN convention on the rights of persons with disabilities. J Law Med Ethics. 2013;41(4):792-806 Table of Contents.

58. Tang CS, Lee YK. Knowledge on sexual abuse and self-protection skills: a study on female Chinese adolescents with mild mental retardation. Child Abuse Negl. 1999;23(3):269-79. https://doi.org/10.1016/S0145-2134 (98)00124-0.

59. United Nations. Convention on the rights of persons with disabilities (CRPD) 2006 [cited 2006. Available from: https://www.un.org/development/desa/ disabilities/convention-on-the-rights-of-persons-with-disabilities/article-12equal-recognition-before-the-law.html.

60. Fraser-Barbour EF, Crocker R, Walker R. Barriers and facilitators in supporting people with intellectual disability to report sexual violence: perspectives of Australian disability and mainstream support providers. J Adult Prot. 2018; 20(1):5-16. https://doi.org/10.1108/JAP-08-2017-0031.

\section{Publisher's Note}

Springer Nature remains neutral with regard to jurisdictional claims in published maps and institutional affiliations.

Ready to submit your research? Choose BMC and benefit from:

- fast, convenient online submission

- thorough peer review by experienced researchers in your field

- rapid publication on acceptance

- support for research data, including large and complex data types

- gold Open Access which fosters wider collaboration and increased citations

- maximum visibility for your research: over $100 \mathrm{M}$ website views per year

At BMC, research is always in progress.

Learn more biomedcentral.com/submissions 